\title{
Station at a crossroads
}

\author{
Frank international discussions need to start immediately if anything is to be salvaged from the space \\ station, whose completion currently relies on the ailing space shuttle.
}

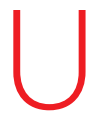
ntil about a week ago, most observers of the space shuttle assumed that the fleet could be kept alive until its planned retirement in 2010 .

But the latest mission of the shuttle Discovery, with its daily litany of stuck fuel gauges, falling foam and chipped tiles (see page 608), raises the prospect that this cannot happen. The ageing shuttle's problems may soon become so difficult to analyse and so expensive to fix that even its staunchest defenders will see that the time has come to stop throwing good money after bad.

What then? The International Space Station is at least 15 shuttle flights away from completion, and that's just counting its largest elements, the European and Japanese laboratory modules and the trusses for solar-power arrays. Several more flights are needed to haul up the experimental racks that would equip the laboratories.

The Russian Soyuz crew vehicle and Progress supply ship are each far too small to carry these large components into orbit. Europe's Automated Transfer Vehicle (ATV), a new cargo carrier scheduled to debut on an Ariane rocket next year, can deliver tons of supplies but not large sections of the station. Japan's proposed cargo carrier, called the HTV, can handle the experiment racks, but won't enter service until 2010. So abandoning the shuttle now would leave the station in its current, half-finished state.

One alternative to that would be for NASA to start work as quickly as possible on a shuttle-derived vehicle (SDV) that would replace the component of the shuttle that carries astronauts with a giant cargo pod. Such an approach is needed anyway for the proposed return to the Moon. In principle, the SDV could deliver the rest of the large pieces of the station, which astronauts, ferried to space on Russian vehicles, could assemble in orbit. In the four or five years it would be expected to take to design and build the SDV, Russian vehicles and Europe's ATV could keep the station aloft, lightly staffed and stocked.

Such a plan would require Europe and Japan to accept yet another major delay to the date on which their labs will enter operation.
They have already stood by helplessly for years, watching NASA make essentially unilateral decisions to scale back the design according to the vagaries of US budget politics. Why should they continue to put up with this?

Well, for one thing, they may not have much choice. But it also runs counter to the interests of the Japanese and European space agencies to watch NASA - which leads most international space projects and will continue to do so for the foreseeable future damage its reputation in further, forlorn efforts to keep the ailing shuttle in space.

The international partners could also make use of the delay to negotiate better terms for their participation in the space-station project. Michael Griffin, the latest NASA administrator, has made no secret of his low regard for the station since his appointment in April. Except for medical research on astronauts and technology tests related to the Moon-Mars programme,
"It runs counter to the interests of Japan and Europe to watch NASA damage its reputation in further forlorn efforts to keep the shuttle in space." NASA's use of it is likely to be scaled back, so it ought to cede more laboratory time, more astronaut participation and more missioncontrol involvement to Europe and Japan.

Such an arrangement would assume that NASA's long-suffering international partners would relish an enhanced role in the project. Publicly, their commitment to the space station is as robust as ever. But if, in truth, they'd rather leave the project in its current state, abandon their laboratory modules, and start spending their taxpayers' money on something more useful, now is surely the time to say so. NASA could then offer something else - probably a prominent role in other cooperative projects - to compensate for reneging on its obligation to complete the US end of the deal. Either way, it's time for some plain speaking and creative thinking, not for stubbornly sticking to an obsolete plan.

It is probably fair to say that many mathematicians feel themselves

\section{Count themselves lucky}

\section{Mathematicians might think they have an image problem, but the public holds them in great esteem.}

ike people in many disciplines, mathematicians are prone to bouts of concern that they have an image problem. Only last -month, some of them convened on the Greek island of Mykonos with a group of writers to consider how a better use of narrative could help them with their work - and with their public relations (see page 622). perceived as unable to conduct the simplest practical task, unfashionably attired, nerdy and isolated from the real world.

A collection of the jokes that mathematicians tell each another (Not. Am. Math. Soc. 52, 24; 2005) reveals an element of self-mockery of their obsessive and pedantic natures. Who else would laugh at the suggestion that what you get by crossing an elephant with a banana is |elephant $|*|$ banana $\mid * \sin \theta$ ?

Additionally, as they are never shy to tell the rest of us, mathematicians receive only a tiny slice of the overall research funding. And although it clearly costs much less to prove a theorem than it does to clone a cow, their small grants are inevitably interpreted 
by mathematicians as a sure sign that their work is undervalued.

These negative associations have been reinforced by a number of popular stories about great mathematicians. The American inventor of cybernetics theory, Norbert Wiener, for example, is frequently depicted as the archetypal absent-minded professor. It is said he once lost his way walking home from the Massachusetts Institute of Technology. He came across a small girl in the street and asked if she could give him directions. "Yes, daddy," she replied, "I'll take you home."

Kurt Gödel, whose incompleteness theorem sent shock waves through mathematics in the 1930s, was a noted misanthrope, who shunned human contact at the Institute for Advanced Study in Princeton, preferring colleagues to communicate via pieces of paper stuffed through the crack beneath the door of his office.

Despite - or, perhaps, because of - such behaviour, the history of mathematics is probably more colourful than that of any other scientific discipline. And there seems to be an insatiable public appetite for tales of the almost supernatural intellectual powers of its more famous figures.

Srinivasa Ramanujan, for example, an Indian mathematician of towering ability in number theory who died at the age of only 32 , first came to the attention of the eminent British mathematician G. H. Hardy by sending his notebooks to him while he worked as a clerk in Madras. Hardy correctly concluded that even if he couldn't follow all of the proofs, only a genius could have thought of the theorems they were seeking to address.

Hardy invited him to Cambridge, but Ramanujan caught a cold that developed into a terminal case of tuberculosis. When Hardy visited his ailing protégé one day by taxi, he commented that the cab's number, 1729, was "rather dull". On the contrary, Ramanujan insisted, it is the smallest number expressible as the sum of two different pairs of cubes.

Earlier eras have produced equally poignant anecdotes. One thinks, for example, of Évariste Galois, the unruly French mathematician who made great strides in group theory. He frantically scribbled down his work for posterity on the eve of his fatal duel in 1832 at the age of just 20. Such stories have pro-

"There seems to be an insatiable public appetite for tales of the almost supernatural intellectual powers of mathematics' more famous figures."

pelled books such as Simon Singh's on Fermat's last theorem to bestseller status.

These tales are popular not just for their panache, but because they celebrate mathematicians as pure intellectuals who, unlike physicists, biologists or chemists, are untainted by applications of their work. For even though mathematics is eminently useful, its application barely features in its public reputation. Disciplines that are traditionally inclined to disdain pure theory - biology springs to mind - should take note of the success with which mathematics, this most theoretical of disciplines, has haplessly bungled its way into people's hearts.

\section{A dog's life}

\section{The first cloned dog was born at some cost, and there needn't be many more.}

$\Lambda$ $\mathrm{n}$ Afghan hound born in South Korea in June adds dogs to the small list of animal species that have been successfully cloned (see page 641). The birth marks another first for the Korean-based group that cloned the first human embryos last year.

The development has some scientific significance, on account of the emerging importance of the dog as a model for the study of certain aspects of human genetics, development, behaviour and disease.

A dog genome project is being undertaken by a US team, and the cloning of dogs could provide an additional tool for researchers. The number of cloned dogs that will be needed for such research is probably small, however. Scientists such as Elaine Ostrander of the US National Human Genome Research Institute, head of the doggenome project, do most of their work with pets living at home, not with kennels of animals bred for research. So the ability to clone dogs is unlikely to have more than a marginal impact on how such research is done.

Cohorts of cloned dogs could potentially be used to study the respective influence of genes and environment on particular traits, however. And if it were possible to derive embryonic stem-cell lines from cloned dog embryos - something that's so far only been done in mice and humans - then canine diseases could be studied more easily in Petri dishes, perhaps providing insights into disease mechanisms and even identifying new therapies. Deriving embryonic stem cells would also pave the way to therapeutic cloning in dogs - perhaps providing a useful animal model for research into human health.

The initial dog-cloning experiment has proven the process to be remarkably inefficient, however, with only two live births - and one survivor - from a total of 1,095 embryos implanted in 123 surrogate mothers. This offers scant prospects for commercial pet cloning, the application of the work that the media is likely to make a fuss about. It is unlikely that even the most
"It is unlikely that even the most obsessive pet owner would contemplate preparing more than 100 failed pregnancies for just one successful birth." obsessive pet owner would contemplate preparing more than 100 failed pregnancies for just one successful birth - especially when there is no guarantee that the cloned dog will behave like the one they hope to duplicate. In such circumstances, the cloning of dogs for pet owners remains ethically indefensible.

The Korean researchers named their new dog Snuppy, for Seoul National University puppy (one can almost imagine the name being chosen - presumably on a conference call with the university press office). Let us wish him a long and happy life and hope that now that the concept behind the birth is proven, dogs are cloned only when strictly required for research purposes, and that effort is concentrated on work that carries the most likely rewards for canine and human health. 